\title{
Impact of dikes in the well productivity: A case study in the Ponta Grossa Dike Swarm
}

Felipe Lisbona Cavalcante ${ }^{1,2}$, Carlos Alberto Mendonça ${ }^{1}$, Ulrich Ofterdinger ${ }^{3}$, Oderson Antônio de Souza Filho ${ }^{4}$ ${ }^{1}$ IAG-USP; ${ }^{2} \mathrm{CAPES}$ - PROEX, ${ }^{3} \mathrm{QUB},{ }^{4} \mathrm{CPRM}$ - CEDES/PR

Copyright 2019, SBGf - Sociedade Brasileira de Geofísica

This paper was prepared for presentation during the $16^{\text {th }}$ International Congress of the Brazilian Geophysical Society held in Rio de Janeiro, Brazil, 19-22August 2019.

Contents of this paper were reviewed by the Technical Committee of the $16^{\text {th }}$ International Congress of the Brazilian Geophysical Society and do not necessarily represent any position of the SBGf, its officers or members. Electronic reproduction or storage of any part of this paper for commercial purposes without the written consent of the Brazilian Geophysical Society is prohibited.

\section{Abstract}

Dike swarms are mega-structures observed in different geological contexts. However, it is very difficult to obtain quantitative information about the units that make up these structures from magnetometric data. This work uses a method that performs the inversion of magnetic data profiles and cluster analysis of obtained solutions. The results are used to interpret the effects of a dike swarm on water-well's productivity. The method is applied to a region in the Ponta Grossa Dike Swarm. The results show that wells located in zones of influence of dikes, which intrude crystalline rocks of high metamorphic grade, are 14.5 times more productive than those located in the host rocks outside these zones. For crystalline rocks of low metamorphic degree, wells in the zones of influence of dikes are 4.3 times more productive than when allocated in the host rocks not affected by the presence of dikes.

\section{Introduction}

Dike swarms are crustal structures identified by magnetic anomalies that may extend laterally for hundreds of kilometers or more. Usually, dike swarms are composed of mafic rocks (diabases, andesites) with tabular geometry, formed during transportation and storage of magma by the nesting rocks in preliminary stages of rifting. A swarm of dikes can significantly affect the flow of groundwater although its effects may be different in different geological contexts. Dikes have been observed to reduce and baffle groundwater flow across their strike (COMTE et al., 2017) or divert groundwater flow preferentially along their strike orientation (SENGER et al., 2015). When hosted in permeable rocks (sandstones, for example), a group of dikes tends to compartmentalize the aquifer system (ROSA FILHO et al., 2003) or redirect the flow of groundwater along the strike (BABIKER and GUDMUNDSSON, 2004). DICKSON et al. (2014) developed a model of hydraulic conductivity from upscaling of field measurements, remote sensing and aeromagnetic data. Flow modelling showed that the dikes act as a barrier to water flow, conditioning the flow regime in the granular porous medium (sandstone).

On the other hand, it is observed under field conditions that dikes present intense fracturing in the form of columnar joints perpendicular to the edges, because of magma body contraction with cooling (EVERDINGEN, 1995). These fractures create a system with interconnected porosity that can increase groundwater storage and transmissivity, creating an aquifer system and preferential pathways inside the fractured dikes or rocks in its vicinity. Especially for dikes warming in low permeable crystalline rocks with a low degrees of primary fracturing, the contribution of the hydraulic permeability of fractured dikes can increase the overall bulk transmissivity of the aquifer system. The understanding of the role of dikes in the aquifer system becomes even more difficult when it comes to nonoutcropping dikes, inferred from aerogeophysical data. In these cases, assessing the impact of dike swarms on the groundwater flow regime can be inferred within the uncertainty associated with the geophysical models and the monitoring well coverage in the region.

This work uses models obtained from the inversion of aeromagnetic data (PyDyke program, CAVALCANTE, 2019) along a transect in the Ponta Grossa Dike Swarm (PGDS). Alternative solutions obtained with the inversion program are classified using group analysis (k-means) to identify sub-groups of dikes associated with wells with higher specific capacity. We first present the structure of data inversion and k-means analysis, illustrating these approaches with numerical simulation testing. Then we present the results obtained in the Ponta Grossa Arch, developing a conceptual model that suggests the association of more productive wells with the fracturing system associated to the emplacement of a distinct group of dikes.

\section{Magnetic data inversion}

The proposed method is composed by the inversion of magnetic data in profiles, cluster analysis and correlation of the results with the well's database. Data inversion and group analysis are implemented in the PyDYKE program, which represents the dike swarm by a set of thin prisms (thin sheets) according to KU and SHARP (1983) formulation. A particular prism, for example the $\mathrm{j}$-th prism of a model with $n$ prisms, is defined by a parameters vector $\mathbf{q}_{j}=\left[a, i_{m}, x_{0}, z_{0}\right]_{j}$, being $a \equiv M e$ the product of the magnetization intensity, $M$, by dike's thickness, $e, i_{m}$ is the inclination of the magnetization, $x_{0}$ is the position along the profile, and $z_{0}$ is the depth of the prism top. The set with $n$ prisms can be organized into an $\mathrm{N}$-dimensional vector $\mathbf{p}$ $(N=4 n)$ such that $\mathbf{p}=\left[\mathbf{q}_{1}, \mathbf{q}_{2}, \ldots, \mathbf{q}_{n}\right]$.

The PyDYKE program has two steps to estimate model parameters. In the first step, PyDYKE fits the intensity of the anomalous vector field (IAVF). For 2D sources the IAVF at the i-th position of the profile is given by $T_{i}=$ $\sqrt{T_{x, i}^{2}+T_{z, i}^{2}}$, being $T_{x, i}$ and $T_{z, i}$ the components $\mathrm{x}$ and $z$ of the anomalous magnetic field. Proton precession magnetometers measure the total field anomaly, $T_{t, i}$, being 
$t$ the direction of the local magnetic field. PyDYKE uses the IAVF to determine a number of prisms $(n)$ that allows data fitting, because each prism entails an inflection or apex in the IAVF profile. The user can add more prisms to specific passages where he judges data fitting is unsatisfactory. The first step of PyDYKE inverts the IAVF minimizing the functional

$$
Q(\mathbf{p})=\sum\left(T_{i}^{o}-T\left(x_{i}, \mathbf{p}\right)\right)^{2}
$$

subject to physical and geological constraints from unknown parameters $\mathbf{p}$. In the functional $Q(\mathbf{p}), T_{i}^{o}$ represents the observed IAVF on the position $\mathrm{i}$ and $T\left(x_{i}, \mathbf{p}\right)$ the equivalent quantity calculated from the model $\mathbf{p}$ on the same position. The minimization of $Q(\mathbf{p})$ determines a model $\widehat{\mathbf{p}}$ such that $Q(\widehat{\mathbf{p}}) \leq \varepsilon$. As the IAVF is invariant with magnetization inclination, the inversion of $Q(\mathbf{p})$ applies an arbitrary value to this quantity $\left(90^{\circ}\right.$, for example). To determine the $i_{m}$ parameter to each prism in the model, the second step of PyDYKE inverts the total field anomaly (TFA), constrained in the interval $i_{m, \min } \leq i_{m} \leq i_{m, \max }$ and "freezing" the parameters in $\widehat{\mathbf{p}}$, obtained in the first step. In its second step, PyDYKE inverts the functional

$$
U(\widehat{\mathbf{p}}+\Delta \mathbf{p})=\sum\left(T_{t, i}^{o}-T_{t}\left(x_{i}, \widehat{\mathbf{p}}+\Delta \mathbf{p}\right)\right)^{2},(\mathbf{2}),
$$

being $T_{t, i}^{o}$ the TFA observed in the $\mathrm{i}$-th position and $T_{t}\left(x_{i}, \widehat{\mathbf{p}}+\Delta \mathbf{p}\right)$ the corresponding value evaluated from the prisms model defined by the vector $\widehat{\mathbf{p}}$ disturbed. The minimization of $U(\widehat{\mathbf{p}}+\Delta \mathbf{p})$ determines a model $\widetilde{\mathbf{p}}$ that fits the measure data such as $U(\widetilde{\mathbf{p}}) \leq \varepsilon_{2}$.

The stepped inversions linking the sequential minimizations of functional $Q(\mathbf{p})$ and $\mathrm{U}(\widehat{\mathbf{p}}+\Delta \mathbf{p})$ have been effective in many schemes for magnetic data inversion (TUMA and MENDONÇA, 2007; LIU et al.2015). In each step, PyDYKE constrains model parameters to give solutions consistent with geological information and magnetization properties of the region under investigation.

\section{K-means analysis}

The PyDYKE module implementing the cluster analysis aims to recover averaged parameters in alternative solutions obtained with the inversion program. The cluster analysis objectively identifies groups of dikes in terms of depth, magnetization inclination, and product of magnetization intensity to prism thickness. This classification is necessary since dike groups with specific properties may affect well productivity in different ways. The cluster analysis also serves to verify if mean parameters in dike distribution are retrieved from alternative solutions of the inverse problem, for example identifying shallow prisms pratically at same positions and comparable properties.

Given a solution of the inverse problem, the starting point of the cluster analysis is the construction of a generic matrix $\mathbf{S}$ of the two-mode type (TUCKER, 1964), such as

$$
\boldsymbol{S}=\left|\begin{array}{ccc}
a_{1} & i_{m, 1} & z_{0,1} \\
\vdots & \vdots & \vdots \\
a_{n} & i_{m, n} & z_{0, n}
\end{array}\right| \text { (3) }
$$

This matrix has size $n \times 3$, being $n$ the number of prisms in the model and 3 the number of each thin-prism parameters in the model, excluding position $x_{0}$. The first column of $S$ contains the product of the magnetization intensity by the dike thickness, the second the magnetization inclination, and the third one the depth to the top.

The k-means technique (JAIN, 2010) starts with random choice of k-centroids to evaluate Euclidean distances $d_{j, i}=$ $\left\|\mathbf{s}_{j}-\mathbf{c}_{i}\right\|^{2}$ between centroids $\mathbf{c}_{i} \quad(\mathrm{i}=1: \mathrm{k})$ and prismparamters (lines of $\boldsymbol{S}$ ). Values $d_{j, i}$ define a matrix of distances, D, with $n \times k$ entries. Every prism of the model can be associated to one of the centroids $\mathbf{c}_{i}, \mathrm{i}=1: \mathrm{k}$ accounting for minimum distances in matrix $\mathbf{D}$. The centroids are updated according to $\mathbf{c}_{i}=\frac{1}{L} \sum_{l=1}^{L} \boldsymbol{a}_{l}$, by identifying the $L$ prisms (lines of $\mathbf{S}$ ) near the centroid $\mathbf{c}_{i}$, repeating the operation for $i=1: k$. The matrix distance and centroid evaluations are repeated until centroid position do not change. The distances matrix is updated and the norm of residuals evaluated according to

$$
V(\mathbf{D})=\sum_{j=1}^{n} \min \left(\mathbf{d}_{\boldsymbol{j}}\right),(\mathbf{7})
$$

where $\mathbf{d}_{j}$ is the minimum distance of the $j$-th line of the matrix $\mathbf{S}$ with respec to the closest centroid identified by the k-means analysis.

The k-means technique demands previous knowledge for the number of groups, $k$, which cannot be asserted a priori in many cases, the group analysis for dikes in particular. A way to overcome this problem consists in evaluating $V(\mathbf{D})$ as in equation 7 for different values of $k$ and stimating an optimum-value such that $V(\mathbf{D})_{k} \approx V(\mathbf{D})_{k+1}$ does not decrease effectively when computed. This minimum value for $k$ can be found by plotting $V(D)$ for variable $k=1: M$, picking in this picture the value $k_{\max }$ from which $V(\mathbf{D})$ flats (TIBSHIRANI, WHALTER e HASTIE, 2001).

\section{Numeric Simulation}

The numerical simulation tests aim to evaluate the potentialities and limitations of the inversion procedure and the group analysis. The model presented here (Model 1) is formed by 40 prisms (160 parameters) distributed in random positions $x_{0}$ along a profile of $30 \mathrm{~km}$ in length ( average density of 1.3 prisms. $\mathrm{km}^{-1}$ ). This multi-prism model was evaluated by the forward problem module of PyDYKE. To simulate a random distribution of prisms, each prism in the model was generated from Gaussian distributions with mean values centred at two centroids in model space $\left(a, z_{0}, i_{m}\right)$ as shown in Table 1 . The purpose of the mode is to simulate two generations of dikes with different geological attributes as expected from dikes generated from different magmatic episodes, each one with different magnetization and depth characteristics.

Table 1: Values used for random generation of prisms of the Model 1. $C_{1}$ and $C_{2}$ are centroides to simulate two dike generations. Model parameters: a, product between the magnetization intensity and the thickness; $z_{0}$, depth to the top, $i_{m}$ magnetization inclination.

\begin{tabular}{|c|c|c|c|}
\hline & $a(\mathrm{~A})$ & $z_{0}(\mathrm{~m})$ & $i_{m}(\stackrel{\mathrm{o}}{)})$ \\
\hline$C_{1}$ & $159 \pm 1 \%$ & $50 \pm 1 \%$ & $58 \pm 5 \%$ \\
\hline$C_{2}$ & $265 \pm 1 \%$ & $200 \pm 1 \%$ & $-58 \pm 5 \%$ \\
\hline
\end{tabular}


Figure 1 shows for alternative models obtained from the inversion of the synthetic data from Model 1. All solutions attends the acceptance criteria $Q(\mathbf{p}) \leq 290$ and $U(\widehat{\mathbf{p}}) \leq$ 640). These alternative solutions were found after applying PyDYKE 400 times, each one starting from random initial models. Each solution contains 33 prisms (132 parameters). Due to interfering patterns, some of the prisms are not clearly identified in the magnetic field but in all cases data fitting degrades if any prism is removed from the model. Once the synthetic data is corrupted with $1 \mathrm{nT}$ of random noise (1000 times the precision of the cesium vapor magnetometer), the proximity of solutions suggests that the proposed procedure is stable.

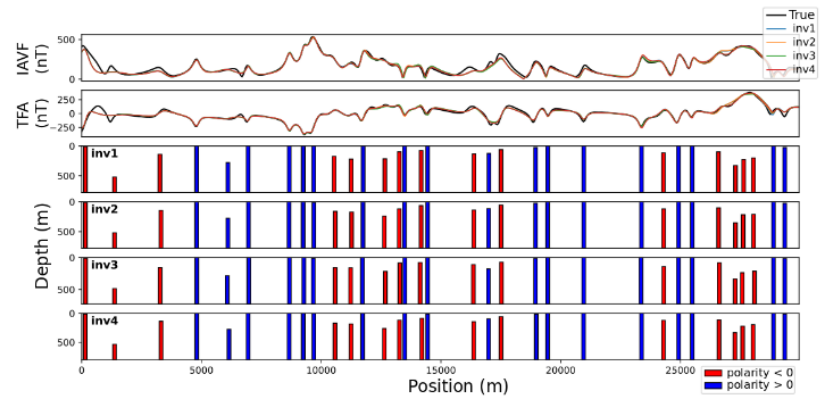

Figure 1: Alternative solutions (inv1, inv2, inv3 and inv4) for synthetic data inversion from Model 1, and data fitting from each model (on top).

The plot of $V(\mathbf{D})$ as a function of $k$ for the four alternative solutions is presented in Figure 2. Worth to note that maximum variation in this curve is observed for $\mathrm{k}=2$ (the correct number of groups in generating the random model), as expressed in the absolute value of $V(\mathbf{D})$ or its derivative. At $k=2$ the curve inflections are high and rather flat onward.

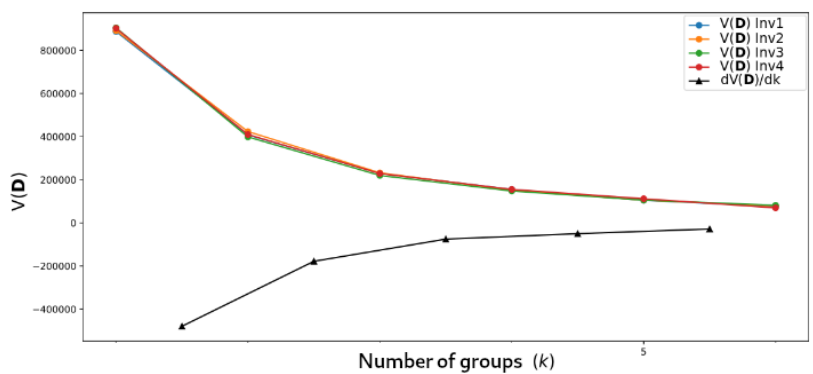

Figure 2: Definition of the number of groups ( $k$ ) from alternative solutions of synthetic data inversion from Model 1. Coloured lines: $V(\boldsymbol{D})$, according to equation (12), to the solutions inv1 to inv4 as a function of $k$. Black line: approximation to the derivative of $V(\boldsymbol{D})$ related to $k$ for inv1.

The cluster analysis module to $k=2$ was applied on the solutions of the model 1 . Figure 3 , shows the centroids obtained for two groups to $\mathrm{z}_{0}$ as a function of $a$. Figure 4 shows the centroids for $i_{m}$ as a function of $a$. In both cases, the centroids for the two groups infer values close to the true model.

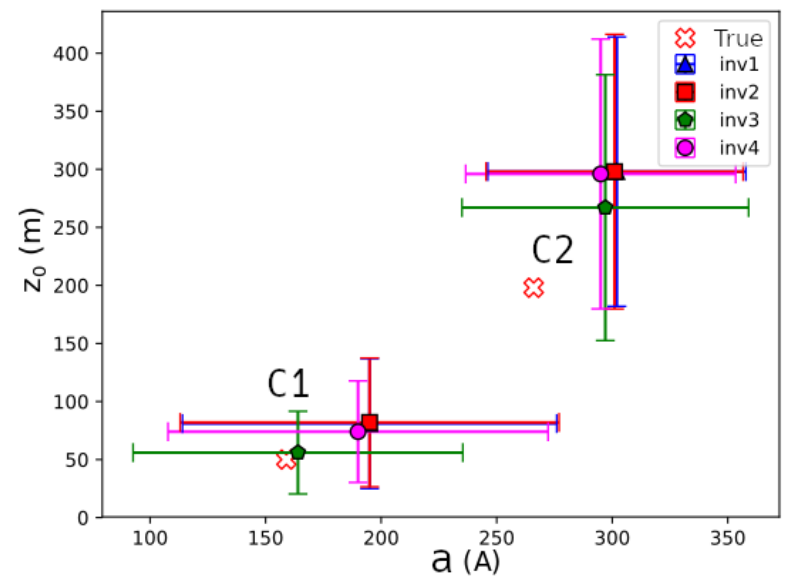

Figure 3: K-means analysis of the Model 1 for the parameters $a$ and $z_{0}$; true centroids $C 1$ and $C 2$ of the true model (red hollow $x$ ) and the correspond alternative solutions (inv1 to inv4). Coloured bars represent the unit's dispersion to each solution.

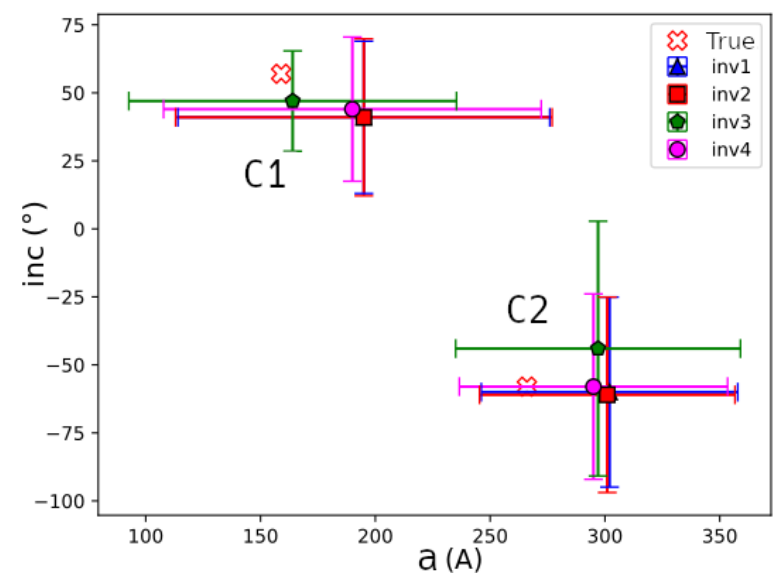

Figure 4: K-means analysis of the Model 1 for the parameters $a$ and inc; true centroids $C 1$ and $C 2$ of the true model (red hollow $x$ ) and the correspond alternative solutions (inv1 to inv4). Coloured bars represent the unit's dispersion to each solution.

\section{Aeromagnetic profile on the PGDS}

The application in real data was performed with data from the aerogeophysical project 1095 Paraná-Santa Catarina from the Brazilian Geological Survey (CPRM, 2011), that covers part of the Brazilian coast, from South of the São Paulo state to the South of the Santa Catarina state. The selected data window (Figure 5) covers the portion of the PGDS in the crystalline basement of the Paraná state. From this window, TFA was used to evaluate the IAVF. The profile A-A' was selected and inverted with PyDYKE. 


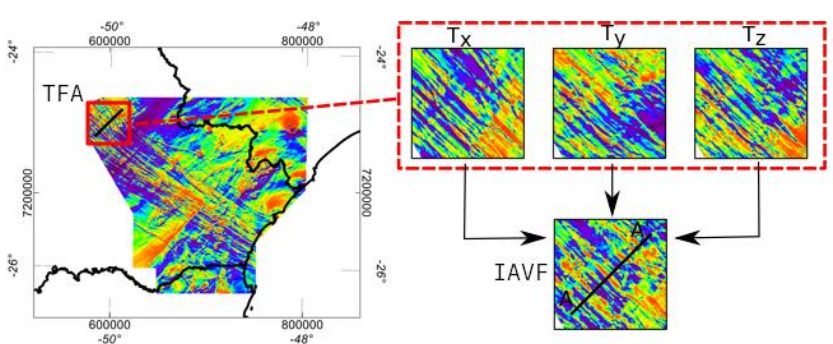

Figure 5: Studied area (red polygon) at Eastern portion of Paraná State. Interpolation of the TFA, computing the components $T_{x}, T_{y}$ and $T_{z}$ to calculate the IAVF. Profile A$A^{\prime}$.

The solutions obtained from the inversion of the profile A$A^{\prime}$ are show on the Figure 6, containing 51 prisms (204 parameters) each. The principal features of TFA and IAVF are fitted, noticing the major presence of normal polarity prisms and minor reverse unities. Shallower prisms are at the initial and end segments of the $10 \mathrm{~km}$ of the profile with density of 1,7 $\sim 1,9$ prisms. $\mathrm{km}^{-1}$. Deeper prisms are at the centre of the profile with density about 0,9 prisms. $\mathrm{km}^{-1}$. We observe algorithm stability, considering that the solutions started from random initial solutions. The best four solutions $(Q(\mathbf{p}) \leq 800$ and $U(\widehat{\mathbf{p}}) \leq 1200)$ were chosen out of 400 solutions.

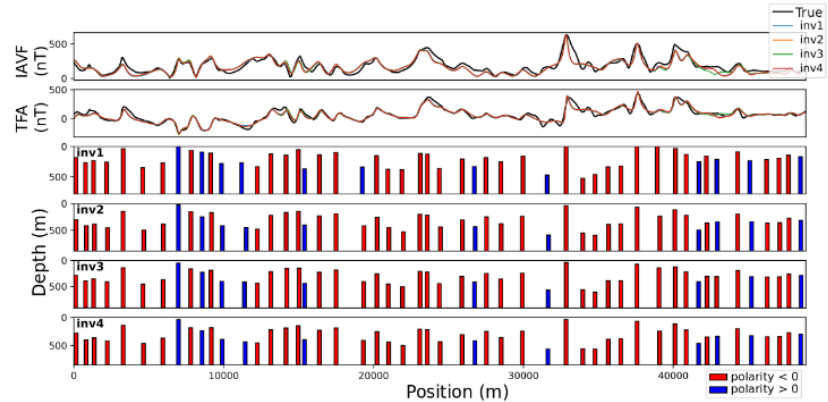

Figure 6: Solutions of the inversion for the profile $A-A$ '. On top, the signal refer to the profile $A-A$ ' is overlaid by the adjusts obtained by the four inversions (inv1, inv2, inv3 and inv4). The disposition of prism obtained from each inversion is on subfigures, inv1 to inv4.

Figure 7 presents the approximation to the derivative of $V(D)$ suggesting a number of clusters $k_{\max }=3$ for the inversed solutions of the profile A-A'.

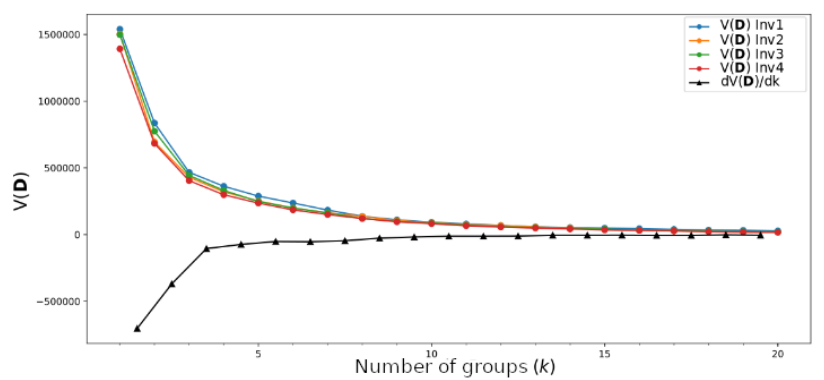

Figure 7: Definition of the number of groups $(k)$ for the models obtained by inversion of the profile A-A'. Coloured lines: $V(\boldsymbol{D})$, equation (12), to the solutions inv1 to inv4 as a function of $k$. Black line: approximation to the derivative of $V(\boldsymbol{D})$ related to $k$ for inv1.
Figure 8 portray the cluster analysis to the results of the inversion of the profile A-A' with $k=3$ (centroids to $a$ by $z_{0}$ ) and on the Figure 9 (centroids to $a$ by inc). Three clearly distinct groups are recognized, $G 1$ group is the shallowest one, $G 2$ possibly recording a reverse magnetization.

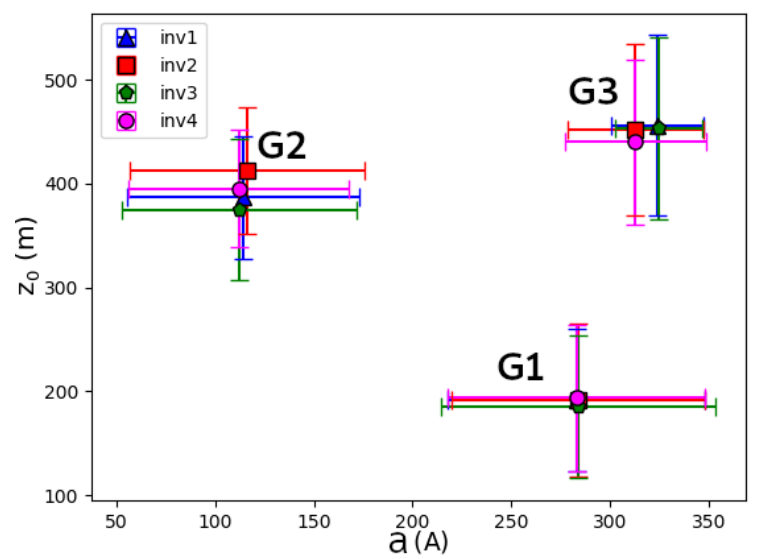

Figure 8: K-means analysis of the profile $A-A$ ' for the parameters $a$ and $z_{0}$; centroids of the alternative solutions (inv1 to inv4). Coloured bars represent the unit's dispersion to each solution. $G 1$ to $G 3$ are dike groups.

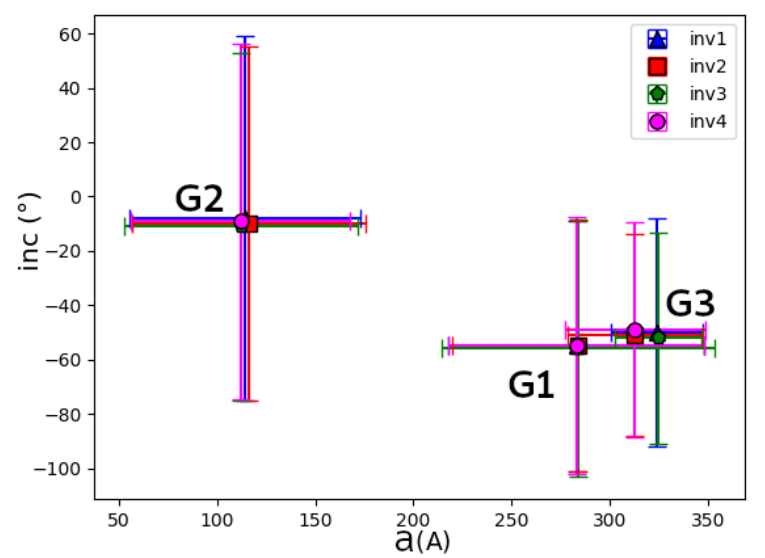

Figure 9: K-means analysis of the profile $A-A^{\prime}$ for the parameters $a$ and inc; centroids of the alternative solutions (inv1 to inv4). Coloured bars represent the unit's dispersion to each solution. $G 1$ to $G 3$ are dike groups.

\section{Water-Wells database analysis}

In this work the well's productivity in the database of the Hydrogeological Map of Parana State (SOUZA FILHO and FRANZINI, 2015) are compared to the dike generations inferred from the cluster analysis. The hydrological database has incomplete information about the lithological profile of the wells, but reliable information about pumping tests, more specifically the depth of the static and pumped water levels (dynamic levels) and the well flow rate. For those wells with different water level depths, the volume of stagnant water in the deeper wells tends to distort yield estimates. This effect is reduced when the specific yield $\left(Q_{S}\right)$ of the well is calculated

$$
Q_{S}=\frac{V_{z}}{n_{e}-n_{d}}(\mathbf{8})
$$


being $V_{z}$ the flow rate, $n_{e}$ the static level of the well and $n_{d}$ it's dynamic level. The wells with $Q_{S}>0$ within the data window were projected on profile A-A' (Figure $10 \& 11$ ) to compare well productivity and groups of dikes as inferred by the cluster analysis (Figure $8 \& 9$ ).

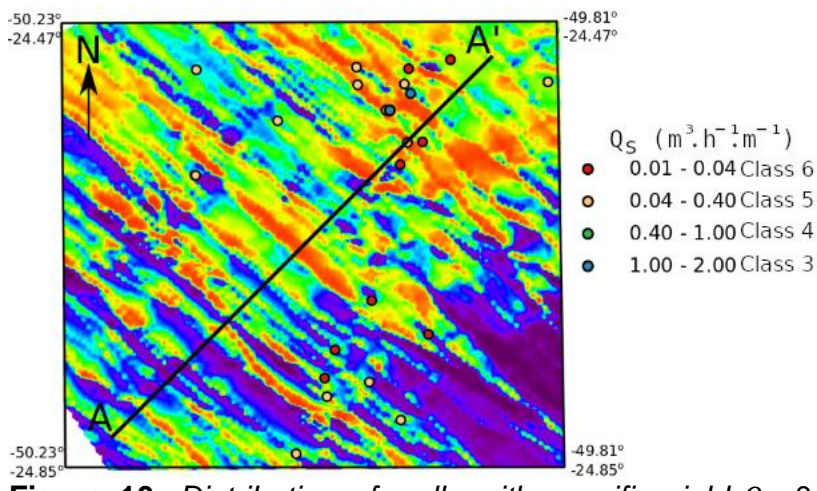

Figure 10: Distribution of wells with specific yield $Q_{S}>0$ over the TFA. Specific yield classes from 0.01 to $2 \mathrm{~m}^{3} . \mathrm{h}^{-}$ ${ }^{1} . m^{-1}$ follows international standardized productivity classes as defined by CPRM (DINIZ et al., 2014).

Figure 11 illustrates the distribution of prisms classified by groups and $Q_{S}$ of the wells projected along the profile A-A' to one of the four similar solutions. We noted that the most productive wells have spatial association with the dike group 1

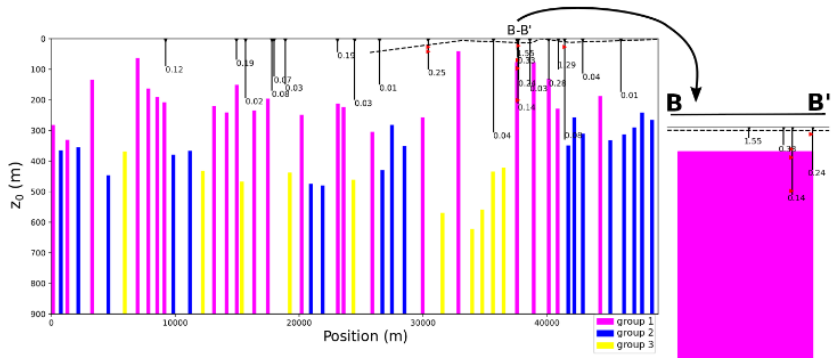

Figure 11: Dike distribution obtained from data inversion and cluster analysis, projection of wells near profile $A-A$ ', and specific yield $\left(Q_{S}\right)$ values $\left(m^{3} \cdot h^{-1} \cdot m^{-1}\right)$. Prism clustering according to k-means analysis of solution inv1: $G 1$ (magenta), G2 (blue), G3 (yellow). Weathered layer depth (dashed line) and points of water entrance (red triangles) according to the database.

The values of $Q_{S}$ as a function of the depth to the top, $z_{0}$, of subjacent dike are show on the Figure 12 (decibel scale). As shown in this figure, the specific yield $Q_{S}$ is inversely proportional to the depth to the top to the subjacent dike unit.

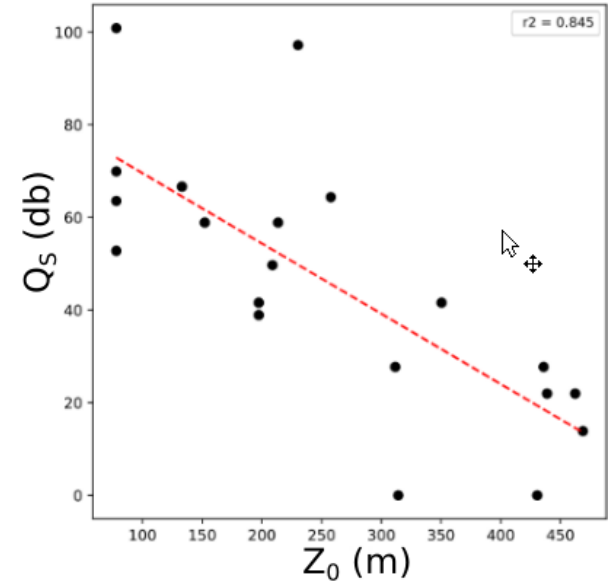

Figure 12: Specific yield $Q_{S}$ of well's and depth to the top of subjacent dikes. Decibel scale according to $\left[20 \log _{10}\left(Q_{S} / 0.01\right)\right]$.

An extrapolation of the results can be made by following the magnetic lineaments of the Analytic Signal Amplitude (ASA) associated to the Dike group 1 (Figure 13). The extrapolation highlights that the wells of class 6 (lowest values of $Q_{S}$ ) do not occur along these lineaments.

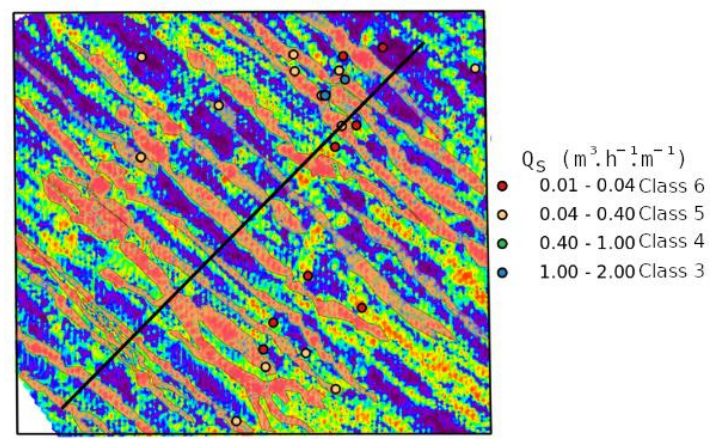

Figure 13: Prisms position for shallow dikes of group 1 (red shadow) inferred from continuity of ASA lineaments.

Figure 14 compares the specific yield, $Q_{S}$, values in two crystalline hosting rocks: a high-grade metamorphic unit (CA) and low-metamorphic unit (CB), with dikes of group 1. This analysis allows differentiating the impact of the Group 1 dikes on the productivity of wells within the different host rocks. For the CA, wells with subjacent dikes are 14.5 times more productive than in those in bare rocks, while for the CB group, the wells on dikes are 4.3 times more productive than in the hosting rocks.
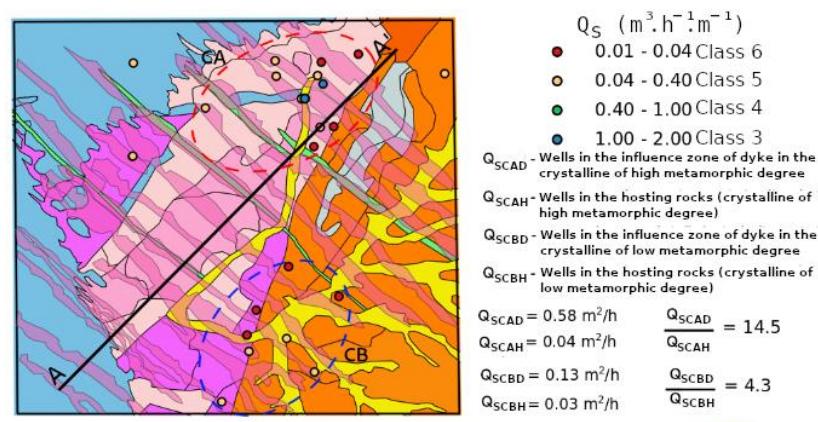

Figure 14: Specific yields $Q_{S}$ on hosting rocks and dikes. Wells classified by specific yield (circles); set of wells (red 
dashed) in the crystalline of high metamorphic degree terrain (CA); set of wells (dashed blue) in the crystalline of low metamorphic degree (CB); magnetic profile $A-A$ '; extrapolation of dike positions of group-1 based on $A S A$ lineaments (shadow magenta). $Q_{S, C A, D}$ and $Q_{S, C A, H}$ are mean specific yield for wells over dikes $(D)$ and hosting $(H)$ $C A$ domain; $Q_{S, C B, D}$ and $Q_{S, C B, D}$ the equivalent quantities for wells at $C B$ domain.

\section{Conclusions}

Previous studies have highlighted that dike intrusions may act either as barriers to groundwater flow or as preferential pathways. The results of the presented study for the profile $A-A^{\prime}$ of the PGDS suggest a relationship between the productivity of wells and dikes, with dikes of the group $G 1$ being associated with more productive wells in the region. The higher productivity may be related to different effects, some of them represented by conceptual models such as Figure 15. However, the lack of lithological description in the available well database limits the conclusions as to which conceptual model best describes the observed effects in the PGDS study region. a)

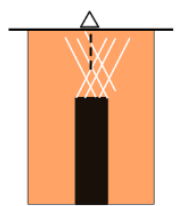

b)

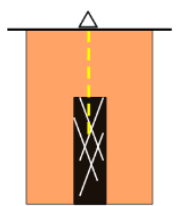

c)

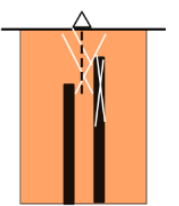

d)

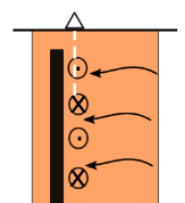

Figure 15: Conceptual models of dikes and well productivity. a) $A$ well (dashed line triangle) intercepts highly fractured/damaged host rock (white lines) related to the dike emplacement. b) A well intercepts an internally fractured dike, whose relative permeability is greater than that of the hosting rock. c) A well intersects a mixed zone, with faults/fracturing in the hosting rock and internally fractured and less permeable competent dikes, generating compartmentalization and connectivity of the water flow. d) A well intersects the more permeable damage zone along strike of the dike, acting as strike-parallel preferential pathway and storage for groundwater and increasing connectivity for primary fractures within the host rock

Further studies are required to better understand the hydrologic effects associated to dike intrusion on respective host rocks and in what conditions more productive wells can be expected. Many variables (host lithology, dike characteristics) are likely to contribute, possibly not all dike unities contributing to the aquifer system.

\section{Acknowledgments}

Thanks to CAPES, IAG-USP, CPRM and QUB.

\section{References}

BABIKER, M.; GUDMUNDSSON, A. The effects of dykes and faults on groundwater flow in an arid land: the Red Sea Hills, Sudan. Journal of Hydrology, 2004. 256-273.

CAVALCANTE, F. L. Inversão 2D de dados magnetométricos com modelo prismático: Aplicação em enxames de diques. Universidade de São Paulo Dissertação de Mestrado, 2019.
COMTE J.C. et al. Effect of volcanic dykes on groundwater flow and saltwater intrusion: a field-scale multiphysics approach and parameter estimation. Water Resources Research, 2017. 10.1002/2016WR019480

DICKSON, N. E. M. et al. Coupling ground and airborne geophysical data with upscaling techniques for regional groundwater modeling of heterogeneous aquifers: Case study of a sedimentary aquifer intruded by volcanic dykes in Northern Ireland. Water Resources Research, 2014. V. 50(10), p. 984-8001.

DINIZ, J. A. O. et al. Manual de cartografa hidrogeológica. CPRM-Serviço Geológico do Brasil, $2014 . \quad 119 \quad$ p. http://www.cprm.gov.br/MHB/Manual_de_Cartografa_Hidr ogeologica.pdf.

EVERDINGEN, D. A. V. Fracture characteristics of Sheeted Dyke Complex, Trodo ophiolite, Cyprus: Implications for permeability of oceanic crust. Journal of Geophysical Research, 1995. V. 100, 957-972.

JAIN, A. K. Data clustering: 50 years beyond K-means. Pattern Recognition Letters, 2010. V. 31(8), p. 651-666.

KU, C. C.; SHARP, J. A. Werner deconvolution for automated magnetic interpretation and its refinement using Marquardt's inverse modeling. Geophysics, 1983. V. 48(6), p. 754-774.

ROSA FILHO, E. F. D. et al. Sistema Aquífero Guarani Considerações preliminares sobre a influência do Arco de Ponta Grossa no fluxo das águas subterrâneas. Revista Águas Subterrâneas, 2003.

SENGER, K. et al. Fracturing of doleritic intrusions and associated contact zones: Implications for fluid flow in volcanic basins, Journal of African Earth Sciences, 2015. http://dx.doi.org/10.1016/j.jafrearsci.2014.10.019.

SOUZA, O. A. de; FRANZINI, A. S. Mapa hidrogeológico do Estado do Paraná: escala 1:600.000. CPRM-Serviço Geológico do Brasil. Mapa e Nota Explicativa, Disponível em: http://rigeo.cprm.gov.br/jspui/handle/doc/17600.2015

TIBSHIRANI, R.; WHALTER, G.; HASTIE, T. Estimating the number of clusters in data set via the gap statistic. Journal of the Royal Statistical Society: Series B (Statistical Methodology), 2001. V. 63, n. 2, 411-423.

Tucker, $L R$. The extension of factor analysis to threedimensional matrices. In Contributions to Mathematical Psychology, 1964. New York, Edited by N. Frederiksen and H. Gulliksen, Holt, Rinehart and Winston. 